\title{
AVALIAÇÕES REPRODUTIVAS OVELHAS EM SISTEMA DE PRODUÇÃO EXTENSIVO
}

\author{
Michele da Rosa Scholant Simões ${ }^{1}$
}

RESUMO: O presente trabalho teve como objetivo uma revisão sistemática das metodologias de avaliação reprodutiva dos ovinos. Tendo como objetivo de avaliar as fêmeas aptas para reprodução, bem como biotecnologias reprodutivas e diagnóstico de gestação ressaltando a importância da literatura aderida ao material prático e a adaptabilidade com a realidade.

Palavras-chave: Sistema. Reprodução. Ovino.

ABSTRACT: The present work had as objective a systematic review of the methodologies of reproductive evaluation of the sheep. In order to evaluate the females suitable for reproduction, as well as reproductive biotechnologies and pregnancy diagnosis, emphasizing the importance of the literature adhered to the practical material and the adaptability with reality.

Keywords: System. Reproduction. Sheep.

\section{FISIOLOGIA REPRODUTIVA DA FÊMEA}

Segundo Del Campo (1980) o aparelho genital da fêmea é responsável não somente pela produção de gametas femininos, mas são também encarregados pela recepção e condução dos espermatozóides, além da nutrição e o cuidado do ser por elas gerados.

O sistema reprodutivo da ovelha é constituído por genitália externa e interna, onde àquela é composta pela vulva e clitóris, e esta pela vagina, cérvix, útero, um par de ovidutos e um par de ovários, de acordo com Pugh (2005), conforme figura cinco. Aisen (2008) cita que a porção anterior da vagina é o local onde o macho deposita o sêmen durante a cópula, já a porção posterior,

\footnotetext{
${ }^{\mathrm{I}}$ Médica veterinária. Doutora em melhoramento genético pela UFPEL.
} 
denominado vestíbulo, faz a comunicação entre o meio exterior (vulva) com a vagina e é o local onde desemboca auretra.

De acordo com Pugh (2005) a cérvix situa-se na porção cranial da vagina sendo composto o canal da cérvix por cinco a seis anéis irregularmente sobrepostos, abrindo- se na porção posterior do útero, sendo este composto de um pequeno corpo e dois cornos ligeiramente espiralados em fêmeas não prenhas.

Galina e Valencia (2006) descrevem o oviduto como sendo um pequeno tubo muscular, constituído por três regiões: o infundíbulo, ampola e istmo.

Para Hafez (2004) o oviduto é dividido em quatro partes, as fímbrias apresentam-se em forma de franjas, o infundíbulo possuindo uma abertura próximo aos ovários envolvendo-os, a ampola, região dilatada distalmente e o istmo porção que está ligada diretamente ao útero.

Os ovários são órgãos bilaterais pequenos, possuem formas ovais, cuja função primária é produzir gametas femininos e a secreção de hormônios (AISEN, 2008).

Segundo Kolb (1980) os ovários são capazes de liberar ovócitos férteis, produzirhormônios, como o estrógeno e formar corpo lúteo, sendo este responsável pela produção de progesterona. Com a ação destes hormônios o ovário é responsável pelo desenvolvimento das características sexuais secundárias.

O tamanho médio dos ovários da ovelha é de $1,5 \mathrm{~cm}$ de comprimento e apresenta quando seccionado, duas partes distintas, a cortical e a medular, onde a primeira compõe a região externa do ovário, e a segunda é revestida por epitélio germinativo e abriga em seu interior folículos e corpo lúteos, de acordo com Mies Filho (1987).

Hafez (2004) relata que a região medular do ovário é constituída por tecido conjuntivo fibro-elástico, nervos e pelo sistema vascular que atingem o ovário pelo hilo, além de possuir folículos e corpos lúteos e várias fases de desenvolvimento e regressão.

Conforme Aisen (2008) as ovelhas possuem uma particularidade no seu ciclo 
reprodutivo, que é a presença de um anestro estacional.

Figura 5 - Esquema do sistema reprodutivo da fêmea com imagens

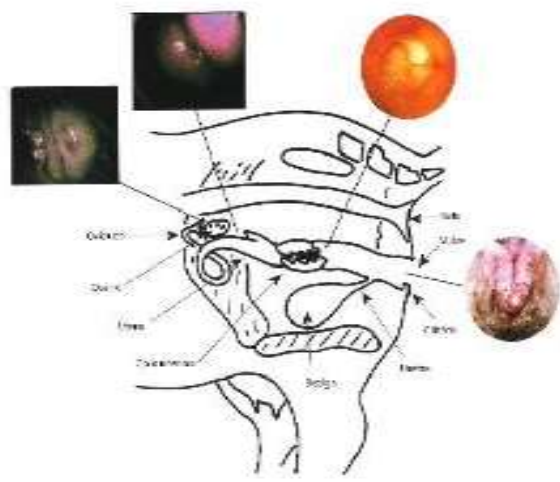

Fonte: $\operatorname{AISEN~(2008)~}$

\section{FOLICULOGÊNESE}

A foliculogênese tem início no final da vida fetal e grande número destes serão degenerados durante o processo de maturação folicular, denominando este evento como atresia folicular, somente a minoria chegará a completar o processo de maturação e ovular (SOUZA, 1998).

Galina e Valencia (2006) citam que a atresia folicular corresponde a 99\% dos folículos existentes no ovário, exceto os que chegam à ovulação.

De acordo com Hafez (2004) o folículo é composto por oócito, células da granulosa e da teca, este conjunto passa por transformações seqüenciais subcelulares e moleculares, controladas por fatores intra-ováricos, intrafoliculares e sinais hormonais levando a secreção de andrógenos e estrógenos caracterizando o crescimento e a maturação deste.

Souza (1998) cita que pode ser dividida a foliculogênese em folículos primordiais, comprometidos, sensíveis a gonadotrofinas, dependentes a gonadotrofinas e folículos ovulatórios, conforme as características fisiológicas de cada um destes grupos.

Os folículos são também chamados de primários, secundários e terciários, conforme o desenvolvimento da foliculogênese (HAFEZ, 2004). 
Estas etapas são assim descritas, conforme Souza (1998) da seguinte maneira:

\section{a) Folículos primordiais}

São formados antes do nascimento e servirão como reserva, de forma que durante toda a vida reprodutiva da fêmea exista folículos para serem recrutados. Os nutrientes são passados em forma de difusão, já que não possuem suprimento sanguíneo próprio. Possuem uma camada achatada de células da granulosa, envolvidas pela membrana basal.

\section{b) Folículos comprometidos}

As ovelhas adultas podem possuir até 400 folículos nesta etapa, estes são os que saem do estágio anterior. As células da granulosa vão se tornando cubóides, começando a possuir receptores para o hormônio folículo estimulante (FSH), ao chegarem neste estágio possuem duas alternativas, ou vão até o final da maturação ou entram ematresia, não sendo possível sua regressão.

Ocorre nesta etapa um crescimento rápido do ovócito, chegando em seu pleno tamanho, bem antes que as células da granulosa cessem sua proliferação.

\section{c) Folículos sensíveis a gonadotrofinas}

Também conhecidos por pequenos folículos antrais, por medirem o, I a 2,5mm. Possuem receptores de FSH nas células da granulosa e de hormônio luteinizante $(\mathrm{LH})$ nas células da teca, mas ainda o suporte de gonadotrofinas não é essencial para seu desenvolvimento. Conforme os folículos vão crescendo, estes começam a produzir uma resposta mediante a ação das gonadotrofinas, iniciando a secreção de níveis aindabaixos de progesterona.

\section{d) Folículos dependentes de gonadotrofinas}

É a fase mais suscetível de atresia, pois dependem diretamente de $\mathrm{FSH}$, sendo esta gonatrofina a responsável pelo crescimento folicular, já que a ação do LH não 
favorece o desenvolvimento de folículos até o estágio pré-ovulatório.

\section{e) Folículos ovulatórios}

As células da granulosa possuem receptores de $\mathrm{LH}$ e no fluído folicular possuem altas taxas de estradiol. Nesta fase os folículos são resistentes a atresia, sendo dominantepor este motivo e podem se tornar ovulatório mediante a um pulso de LH de alta freqüência.

\section{CICLO ESTRAL}

Souza (1998) afirma que as fêmeas ruminantes, em condições onde o ambiente é favorável, apresentam cios regulares quando não estão prenhes, caracterizadas como poliéstricas. O ciclo estral tem duração média de iłdias nas ovelhas, e durante este período ocorre uma série de eventos que são interrompidas em caso de prenhez (pelo impedimento da luteólise) ou pelo anestro estacional.

Ainda este autor cita que existem eventos que ocorrem durante o ciclo estral, sãoeles: desenvolvimento folicular, cio, ovulação, luteinização, desenvolvimento do corpo lúteo, função plena do corpo lúteo e luteólise, caso não haja prenhez o ciclo se repete.

Para Aisen (2008) é considerado fase folicular o período do proestro e estro, e dafase lútea, o período do metaestro e diestro.

Estes eventos são ocorridos de forma bem demarcada sendo denominadas como proestro, estro, metaestro e diestro, de acordo com Kolb (1980). São assim descritas segundo este autor:

\section{a) Proestro}

Com duração média entre dois a três dias nos ruminantes; esta fase tem influência do FSH responsável pelo desenvolvimento do epitélio folicular e do hormônio estimulante das células intersticiais (ICSH) que desencadeia a produção de estrógenos. O aumento desses eventos leva ao cio. 
b) Estro

Também chamado de cio, é o período de receptibilidade sexual, tendo sua duração de 24 a zohoras com intervalos de 16 a i7dias. Nas horas finais do cio, é quando existe maior chance de fecundação, já que a ovulação ocorre neste momento.

c) Metaestro

Ocorre após a ovulação, nesta fase é onde se forma no local da ovulação um tecido funcional denominado corpo lúteo, responsável pela produção de progesterona.

\section{d) Diestro}

$\mathrm{Na}$ ausência da fecundação ocorre uma regressão do corpo lúteo em um período médio de dez dias após a ovulação. Este processo é desencadeado através da prostaglandina $\mathrm{F}_{2} \alpha$ produzida pelo endométrio, a partir do $13^{\circ}$ dia do ciclo estral, diminuindo o aporte sanguíneo para esta região.

\section{PUBERDADE}

Para Del Campo (1980) a puberdade é definida como sendo o início do desenvolvimento dos processos reprodutivos, estes iniciados antes que o animal apresente seu completo desenvolvimento corporal.

A puberdade é influenciada por fatores como idade, condição corporal e clima, oque pode retardar ou acelerar o processo; e também depende da interação entre hipotálamo juvenil, pituitária anterior e ovário (PUGH, 2005).

Hafez (2004) cita que a idade da primeira ovulação ocorre entre o sexto e nono mês de idade em raças de corte, por serem mais precoces que raças laneiras; estas por sua vez chegam à puberdade geralmente a partir da segunda estação sexual entre dezoitoe vinte meses. 


\section{SAZONALIDADE}

Para Galina e Valencia (2006), as alterações ocorridas em função da alternância de luminosidade, são mais acentuadas para animais distantes da linha equatorial, ondeos ovinos podem mostrar períodos de anestro estacional.

A atividade reprodutiva apresenta-se mais prolongada ao longo do ano em regiões mais próximas a linha equatorial, onde a influência da disponibilidade de alimentos depende mais do regime de chuvas do que a quantidade de horas de luz por dia (AISEN,2008).

A finalidade da sazonalidade é de garantir que os nascimentos ocorram na época do ano mais favorável para as crias, na qual a temperatura do ambiente $e$ disponibilidade de alimento é mais adequada (GALINA e VALENCIA, 2006).

\subsection{Inseminação Artificial}

De acordo com Neto (2008) a inseminação artificial tem como vantagem para o sistema de produção de ovinos a utilização de reprodutores com melhor genética, diminuindo o número de machos durante a estação reprodutiva, podendo ser utilizado em mais de uma ovelha o sêmen de somente um ejaculado.

\subsubsection{Inseminação por Laparoscopia}

Leão (2003) cita que a utilização desta técnica, o sêmen é depositado no lúmen dos cornos uterinos possibilitando a utilização de um menor número de espermatozóides.

A laparoscopia viabiliza o uso do sêmen congelado, apresentando uma taxa de concepção de 65 a 80\%. (AX, 2000 citado por LEÃO, 2003).

Para Pugh (2005) esta técnica é desenvolvida com o animal em jejum alimentar e hídrico, 24 horas antes do procedimento, utiliza-se sedação para posterior contenção em decúbito dorsal com a cabeça para baixo ao ângulo de $45^{\circ}$, esta angulação é feitapara que a vesícula urinária se afaste do útero no momento do procedimento, tricotomia, higienização na região abdominal e infiltração anestésica 
a cinco centímetros cranial ao úbere e quatro centímetros lateral a linha média, em ambos os lados, resultando nos doispontos onde ocorre às incisões.

Segundo Aisen (2008) a primeira inserção é realizada com trocarte perfurando a parede abdominal e o omento chegando à cavidade abdominal. Em seguida introduz-seo laparoscópio para visualização dos cornos uterinos.

Após a introdução do laparoscópio, administra-se via a esta inserção um a dois litros de dióxido de carbono, e em seguida realiza a segunda inserção no lado oposto para introduzir um aplicador de inseminação (PUGH, 2005).

Aisen (2008) cita que o aplicador serve para manipular, ajudando para retirada do omento ou outros tecidos, podendo utilizar também na manipulação uterina. Após a exposição da agulha de inseminação, perfura-se com movimento rápido a parede uterina em um ângulo de $90^{\circ}$, certificando que o instrumento encontra-se dentro do útero, deposita-se a dose de sêmen, podendo dividir esta dose em ambos os cornos. Após retira-se o aparelho e o gás carbônico da cavidade abdominal. Aplicando anti-séptico e repelente, libera-se o animal anotando os dados em uma planilha de inseminação.

Pode-se utilizar um número de espermatozóides em torno de io a 50 milhões com resultados de fertilidade satisfatórios, porém, a implantação desta técnica é dispendiosa nem sempre sendo possível seu uso a campo (AISEN, 2008).

\subsubsection{Inseminação Cervical Superficial}

De acordo com Aisen (2008) a fêmea deve ser contida de modo que a parte posterior fique mais elevada que a anterior, para isso pode ser utilizado o método de barras onde o animal é apoiado sobre a tábua superior do curral, apropriado para esta espécie.

Para Pugh (2005), depois de devida contenção do animal, introduz-se um espéculo aginal com luz própria na vagina, para visualização da entrada da cérvix, onde nesse ponto o técnico introduz a pipeta de inseminação através do espéculo para a inseminação ser realizada, podendo tentar ultrapassar os anéis, o que quase 
sempre não ocorre, devido à posição destes, cuja forma é sobreposta ocorrendo à deposição do sêmen na porção caudal da cérvix.

Dun (1960) citado por Del Campo (1980) relata que o método de montar a ovelha em cavaletes, para realização do serviço de inseminação, possui como desvantagem o acúmulo de muco no fundo de saco vaginal, o que resulta em dificuldadepara visualização do orifício cervical e dispersão do inseminado.

Um método eficiente de contenção das ovelhas é a utilização de troncos de contenção giratórios, os quais possibilitam uma maior dinâmica no trabalho, pois quando o técnico realiza o serviço em um animal, um funcionário já prepara o outro aser inseminado (DEL CAMPO, 1980).

\subsubsection{Inseminação Transcervical}

De acordo com Pugh (2005) é uma técnica invasiva, cujo objetivo é a deposiçãodo sêmen no interior do útero. Para este processo é necessária a contenção do animal emsuportes para este fim, ou improvisar para que um auxiliar segure a fêmea com os membros pélvicos puxados para trás.

A técnica tem início com a introdução de um espéculo vaginal Plexiglas, projetado com abertura de um centímetro em todo seu comprimento (PUGH, 2005).

Segundo Aisen (2008) após a tração da cérvix até a vulva, com auxílio das pinças Bozeman, localiza-se o canal cervical e após introduzir o aplicador de sêmen até a luz uterina e posterior deposição do mesmo.

Segundo Rabassa et al (2007), com a tração da cérvix é possível manipular o aplicador através dos anéis cervicais.

Aisen (2008) relata que não é possível a transposição da cérvix em todas as fêmeas, exigindo mais tempo e trabalho por animal.

\subsection{Diagnóstico de Gestação}

Aisen (2008) cita que o diagnóstico de gestação é de fundamental importância para acompanhar o processo reprodutivo adequando as necessidades nutricionais 
das ovelhas e eliminar ventres improdutivos.

Calamari et al (2003) cita que para adoção de biotecnologias, como a inseminação artificial e transferência de embriões, o diagnóstico de gestação é de fundamental importância para a fim de monitorar os índices de fertilidade do rebanho submetido a estas técnicas.

Segundo Santos et al (2004) pode ser diagnosticado a gestação de forma presuntiva, principalmente nas primíparas, observando as modificações das glândulas mamárias, aliado ao não retorno do cio, após cobertura ou inseminação artificial, palpações abdominais, reto-abdominais e distensões abdominais, estas alternativas são de baixa acurácia e tardias, possuindo valor limitado.

De acordo com Bicudo (2008) por vários anos foi utilizada a técnica de ultrasonografia através do efeito Doppler ou modo A, no qual as ondas ultra-sonográficas refletidas são captadas por um equipamento que transformava estas ondas em sinais luminosos ou sonoros. Este método pode ser encontrado nos dias atuais, pois sua acurácia é em torno de 90\% após sessenta dias de gestação.

Ainda este autor cita que a partir da década de 8o, começou a ser utilizadotécnicas de ultra-sonografia por imagens (modo B).

\subsubsection{Ultra-sonografia}

De acordo com Boyezuk (2008) ondas ultra-sonográficas são ondas de pressãode freqüência superior aos audíveis pelos seres humanos, ou seja, acima de 20.000 Hertz.

Ainda este autor cita que a energia elétrica captada pelos cristais de Piezelétricos, fazem estes se expandirem e contraírem, resultando em sons ultrasonográficos, os quais vão se propagar, e ao encontrar uma superfície, ressoa conformea densidade desta, e ao retornar ao aparelho, são convertidos em imagens.

Segundo Bicudo (2008) para uma clareza na imagem, é necessário que não tenha presença de ar entre a probe e a superfície em contato, para evitar este ocorrido, utiliza- se lubrificante a base de carboximetilcelulose. 
Ainda o autor cita que há dois métodos para a realização do exame, sendo umvia transretal e outro transparietal, onde o primeiro é realizado com uma sonda de pequeno calibre lubrificada, introduzida no reto, onde se faz uma varredura em busca da imagem ultra-sonográfica correspondente ao útero e o segundo método, a probe é lubrificada e colocada em contato com a região paramamária, onde naturalmente a ovelha apresenta uma menor quantidade de lã, de preferência deve ser examinada do lado direito, realizando movimentos de mudança de ângulo da probe e deslizamento sobre a parede abdominal.

Garcia (1993) citado por Simões (2008), enfatiza que a probe transretal para diagnóstico de gestação deve ter cinco Mega Hertz $(\mathrm{MHz})$ de freqüência, possibilitando uma identificação de áreas anecogénicas ou vesículas embrionárias, a partir do vigésimodia de gestação.

De acordo com Aisen (2008) o ultra-som possui diversas aplicações em pequenos ruminantes, fornecendo informações gerais do trato reprodutivo e informações sobre prenhez, como diagnosticar precocemente gestações, gestações múltiplas, viabilidade fetal, idade aproximada gestacional e auxilia na formação dos lotes de parição.

Santos et al (2004) citam que o período após 30 dias da cobertura é mais adequado para diagnosticar gestação por ultra-sonografia via abdominal, pois a partir doqual surgem imagens do fluído uterino que se torna evidente após 40 dias de gestação, conforme figura 6.

Antes do $35^{\circ}$ dia de prenhez o exame trans-retal oferece uma maior segurançanos resultados quando comparado com abdominal, já no período entre $35^{\circ}$ ao $70^{\circ}$ dia degestação estas vias se equivale em precisão de prenhez, e a partir da segunda metade da gestação, a via abdominal é a de eleição (AISEN, 2008).

Ishwar et al (1995) citados por Moraes et al (2008) descrevem as principais imagens que caracterizam uma gestação, são elas: a presença de líquido intrauterino, visualização da vesícula embrionária, placentomas, identificação fetal, batimentos cardíacos e movimentos do mesmo. 
Figura 6 -Representação esquemática da cronologia dos eventosultrasonográficos que caracterizam a gestação

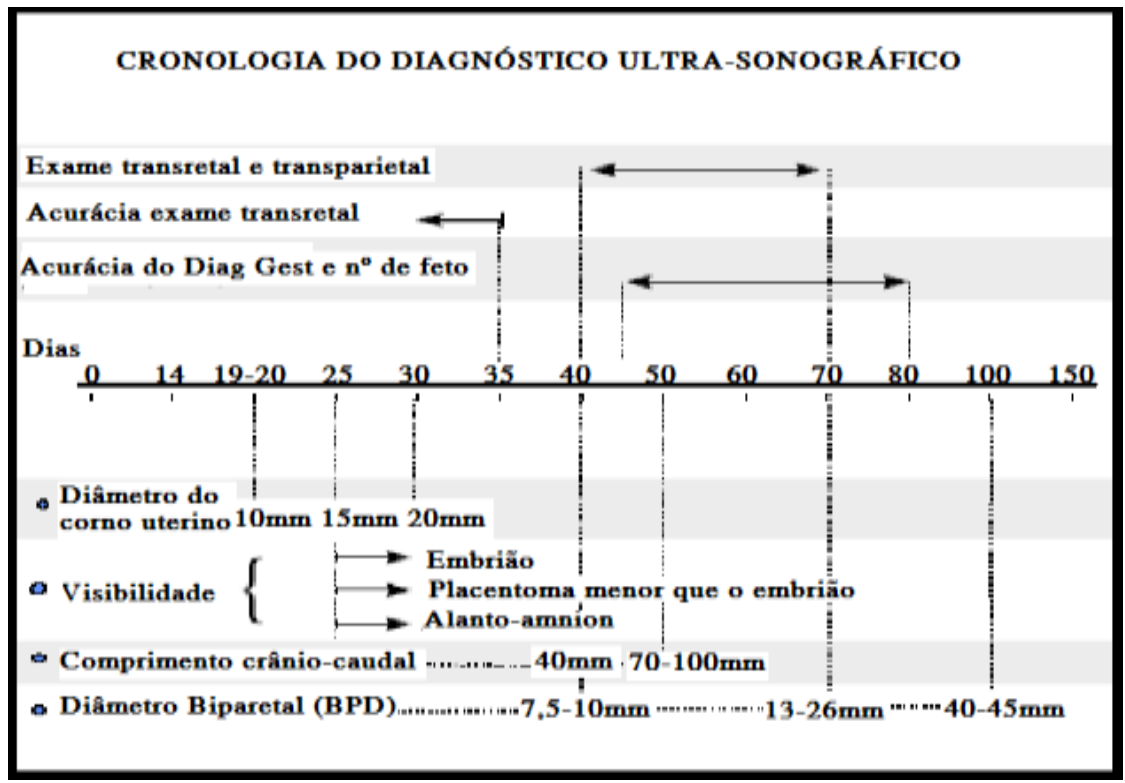

Fonte: Kàhn (1994) adaptado por Bicudo (2006)

\section{INSEMINAÇÃO ARTIFICIAL POR LAPAROSCOPIA}

Uma ferramenta utilizada para obter taxas repetitivas na concepção quando utilizado sêmen congelado concordando com Moraes (2002) e Rabassa et al (2007) citam que o fator limitante à baixa resistência do sêmen congelado após o descongelamento, e a técnica de inseminação no interior do útero alcança bons resultados.

Pugh (2005) comenta que esta técnica requer equipamentos adequados, mão-deobra técnica qualificada, tornando onerosa esta inseminação, concordando com Aisen (2008) e Moraes (2002) quando cita que existem poucos grupos equipados atuando no país.

Aisen (2008) concorda com Leão (2003) quando este cita que a utilização desta técnica possibilita utilizar um menor número de espermatozóides. Concordando tambémcom Pugh (2005), onde descreve a utilização de 50 milhões de 
espermatozóides.

No estágio não se utilizou anestesia local, foi administrado o,2ml de Sulfato de Atropina intramuscular para ocorrer uma breve sedação, discordando de Rabassa et al (2007) e Pugh (2005) onde descrevem a técnica utilizando anestésico no local das incisões.

Para Pugh (2005) é necessária a realização de suturas ou grampos, discordando da técnica utilizada no local do estágio.

\section{INSEMINAÇÃO ARTIFICIAL VIA CERVICAL SUPERFICIAL}

Concorda-se com Del Campo (1980) quando este descreve a utilização de troncos de contenção giratórios próprios para ovinos, otimizando o trabalho. Porém a aquisição deste tronco pode não ser viável economicamente em algumas propriedades.

Neto (2000) concorda com Pugh (2005) sobre a deposição do sêmen utilizando aplicador específico para a técnica, e também concordam entre si quanto ao local de deposição da dose, na entrada da cérvix ou alguns centímetros no seu interior, haja vistaa dificuldade de transpor os anéis cervicais desta espécie.

FUNDAÇÃO BRADESCO (2006) relata que a seringa do aplicador de sêmen deve estar graduada de maneira onde cada ovelha seja inseminada, com no mínimo o,05ml de sêmen. Mies Filho (1987) concorda e salienta que a dose mínima inseminante deve conter aproximadamente 50 milhões de espermatozóides em sêmen fresco. Já Moraes (2002) discorda com este autor, pois para o mesmo, a dose empregada deve conter em torno de 300 milhões de espermatozóides, para que seja possível uma taxa de fecundação superior a 60\%.

\section{ULTRA-SONOGRAFIA}

De acordo com Aisen (2008) o uso do ultra-som é aplicado em pequenos ruminantes, utilizando sonda cinco ou $7,5 \mathrm{MHz}$, concordando com Rabassa et al (2007) que utilizaram em uma pesquisa, ultra-sonografia trans-abdominal sonda 
linear de $5 \mathrm{MHz}$, quarenta e cinco dias depois de inseminar o rebanho.

Santos et al (2004) concordam com Aisen (2008) quando este relata as épocas mais adequadas para utilizar a ultra-sonografia num rebanho para diagnosticar prenhez, sendo a partir de 30 dias após inseminação, e para visualização de feto a partir do terceiro mês. Concordam entre si na escolha da sonda entre três a $3,5 \mathrm{MHz}$ quando utilizada a via abdominal.

Hafez (2004) concorda com Aisen (2008) sobre a utilização de transdutores de baixa freqüência, ocorrendo assim uma visualização mais profunda por via transabdominal comparada com as de alta freqüência.

Buckrell (1988) citado por Ishwar (1994) concorda com Aisen (2008) sobre a probabilidade de ocorrer falso negativo em gestação inicial quando utilizando sonda trans-abdominal.

Santos et al (2004) concordam com Ishwar (1994) sobre as estruturas encontradas com a confirmação da prenhez tais como os placentomas, vesícula embrionária, feto. Após $25^{\circ}$ dia de gestação é possível distinguir batimentos cardíacos.

\section{OUTROS MÉTODOS DE DIAGNÓSTICO GESTACIONAL}

Pugh (2005) concorda com Neto (2000) e Santos et al (2004) quando estes relatam a palpação do úbere como sendo um método presuntivo de gestação, onde em ovelhas prenhes, esta glândula encontra-se em hipertrofia preparando-se para lactação, sendo mais preciso a partir de ıoo dias de gestação.

Para Santos et al (2004) o retorno ao cio, após a inseminação ou cobertura é uma forma de diagnosticar ausência de prenhez. Hafez (2004) concorda com este autor e acrescenta que em ovelhas prenhas o concepto inibe a regressão do corpo lúteo impedindo o retorno do cio.

Aisen (2008) concorda com Pugh (2005) sobre a palpação direta como sendo uma técnica de baixo custo e manejo simples, porém não oferece grandes benefícios. Para diagnosticar a prenhez deve-se sentar uma ovelha por vez e palpar a região 
abdominal e considera-se como positiva, ovelhas com abaulamento flutuante nesta região.

Outro método de diagnóstico de gestação é a utilização de um bastão via retal e concomitante palpação da parede abdominal para observar a presença da gestação ou dobastão, sendo bastante eficaz após $65^{\circ}$ dia de gestação, porém pode ocorrer erro de interpretação quando o bastão se localizar lateralmente ao útero, podendo ocasionar um falso negativo, concordando com Aisen (2008).

Aisen (2008) concorda com Pugh (2005) quando este destaca o efeito Doppler como sendo efetivo após a segunda metade gestacional. Este diagnóstico é feito viaretal, onde o aparelho envia ondas de comprimento curto e freqüência alta que ao deparar-se com objeto em movimento são refletidos ao local da emissão, alterando sua freqüência tornando-o um estímulo luminoso ou sonoro.

\section{CONCLUSÃO}

Revisar as metodologias de avaliações reprodutivas nos ovinos, bem como conhecer as biotecnologias para acrescentar a produção se faz necessáro, já que a reprodução é um dos pilares para obter êxito dentro de uma propriedade rural.

Os avanços nos sistemas de criação dos ovinos estão cada vez mais constates fazendo com que o agronegócio busque com frequência os meios descritos neste trabalho para tornar-se um meio rentável na ovinocultura.

\section{REFERÊNCIAS BIBLIOGRÁFICAS}

AISEN, E.G. Reprodução ovina e caprina. Io Ed. São Paulo: Medvet Livros, 2008. I3; 8; 12-18; 57-66; 77-78; 81; 105-108; 122-127pg.

BICUDO, S. D. Bases para a elevação da eficiência reprodutiva dos rebanhos ovinos. In: SIMPÓSIO PAULISTA DE OVINOCULTURA, 7, Botucatu: 2006. FMVZ-UNESP.

BOYEZUK, D.A. Comunicação pessoal. Curso de ultrasonografía reproductiva bovina e ovina, ginecológica e obstétrica. Paysandú, outubro, 2008. 
CALAMARI, C.V.; FERRARI, S.; LEINZ, F.F.; RODRIGUES, C.F.C.; BIANCHINI,

D.; FERREIRA, F.; DIAS, R.A. Avaliação de dois métodos de diagnóstico precoce de gestação em ovelhas: ultra-sonográfia transretal e detector de prenhez para pequenos ruminantes. Brazilian journ al of veterinary and animal science. São Paulo: 40: p. 26I-266. 2003.

DEL CAMPO, A.D. Anatomia, fisiologia de la reproduccion e inseminacion artificial en ovinos. Uruguai, Editorial Hemisferio Sur, 1980, p. 6; 27-28; 31-33; 57-59;

I24-I25; I29-I33; I43-I44; I48-I49; I90-I95.

EGON, J.F. e MORAES, G.V. Reprodução dos animais domésticos. Maringá, ebook,2005.

FUNDAÇÃO BRADESCO, Curso de Inseminação Artificial em Ovinos. 2006, p. I4-I5; I7-I8; 23.

GALINA, C. e VALENCIA, J. Reproducción de los animales domésticos. $2^{\mathrm{o}}$ Ed.México: Limusa, 2006. p. 38; 85-86; 101-102; 105-109; 121-123; 136-137.

GONZÁLEZ, F.H.D. Introdução à endocrinologia reprodutiva veterinária. Porto Alegre: Gráfica UFRGS, 2006, p. 50-56 e 8o-84.

GRANADOS, L.B.C. Aspectos gerais da reprodução de caprinos e ovinos. $I^{\circ} \mathrm{Ed}$. Campos dos Goytacazes: Universidade Estadual do Norte Fluminense Darcy Ribeiro, 2006, p. I2.

HAFEZ, E.S.E e HAFEZ B. Reprodução animal. $7^{\circ}$ Ed. São Paulo: Manole, 2004. p.5-9; I3-2I; 57; 69-73; 97-98; IOI; 103-IO4; III-II2; 370; 377-378; 390; 399-403; 40I-

402.

IBGE. Dados sobre população ovina 2006. Disponível na internet em:www.ibge.com.br. Acesso: 1o de setembro de 2008.

ISHWAR, A.K. Pregnancy diagnosis in sheep and goats. India, Ranchi VeterinaryCollege, Small Ruminant Research, v. 17, 1995, p. 37-44.

KOLB, E. Fisiologia veterinária. 4. Ed. Rio de Janeiro: Guanabara Koogan S.A., I980,p. 382-384; 385-386; 388-391. 
LEÃO, K.M. Técnicas de inseminação artificial. Botucatu, 2003, p. 14-17.

MIES FILHO, A. Reprodução dos animais e inseminação artificial. Volume i e 2. $6^{\circ}$ Ed. Porto Alegre: Sulina, I987. p. 45; 52-53; 62-70; 98-IO4; IIo-II5; 368-380; 413;

418-419; 424-425; 439-440; 491; 513; 618.

MORAES, E.P.B.X.; SANTOS, M.H.B.; FILHO, C.R.A.; NEVES, J.P.;

OLIVEIRA,

M.A.L.; LIMA, P.F. Avaliação ultra-sonográfica do desenvolvimento embrionáriofetal de ovinos da raça Santa Inês. Ciência Animal Brasileira. Goiânia; v. 9: nº 1 : I48-I55, janeiro/março. 2008.

MORAES, J.C.F. O emprego da inseminação artificial nas ovelhas. Ministério daAgricultura, pecuária e abastecimento. Circular técnica. Bagé: 25: 6p, junho. 2002.

NETO, A.F. Ovino-caprinocultura, acreditando nas oportunidades, superando desafios. Informativo AGROSUL. Porto Alegre, p.39-40, julho. 2008.

NETO, O.A.P. Manejo reprodutivo de ovinos. Porto Alegre: SENAR - Serviço Nacional de Aprendizagem Rural. p. 13-16; 33. 2000.

PUGH, D.G. Clínica de ovinos e caprinos. I. Ed. São Paulo: Roca Ltda, 2005, p. 145I53; I64-I66; 174-176; 179-18I.

RABASSA, V.R.; TABELEÃO, C.V.; PFEIFER, L.F.M.; SCHNEIDER, A.; ZIGUER, E.A.; SCHOSSLER, E.; SEVERO, N.C.; PINO, F.A.B.D.; CORREA, M.N. Efeito das

técnicas transcervical e laparoscópica sobre a taxa de prenhez de ovelhas inseminadas em tempo-fixo. Goiânia: Ciência Animal Brasileira, janeiro/março, 2007 , v. $8, \mathrm{n}^{\circ}$ I p. $127-133$.

SANTOS, M.H.B.; OLIVEIRA, M.A.L.; FERNANDES, P. Diagnóstico de gestação na cabra e na ovelha. I. Ed. São Paulo: Varela, 2004. p. 32-40; 43-50.

SIMÕES, J.; FONTES, P., ALMEIDA, J.C. Diagnóstico de gestação e de patologias uterinas por ecografia em ruminantes, eqüinos e suínos. Versão online, 2008, p. 33- 40. 